\title{
Pregnancy Outcomes in Cases of Preterm Prelabor Rupture of Membranes at Aswan University Hospital
}

\author{
Alhoussain Mohamed Fahmy*1, Abdou Saeed Ait-Allah ${ }^{2}$, Laila Ezzat Abdel Fattah ${ }^{1}$ \\ ${ }^{1}$ Department of Obstetrics and Gynecology, Faculty of Medicine, Aswan University, ${ }^{2}$ Department of Obstetrics \\ and Gynecology, Faculty of Medicine, Sohag University, Egypt \\ *Corresponding author: Alhoussain Mohamed Fahmy, Mobile: (+20) 1015712838
}

\begin{abstract}
Background: Preterm premature rupture of the membranes (PPROM) is a pregnancy complication. In this condition, the sac (amniotic membrane) surrounding baby breaks (ruptures) before week 37 of pregnancy. Once the sac breaks, there will be an increased risk for infection. There will be also a higher chance of having baby born early.

Objectives: The aim of the work was to determine the maternal and fetal outcomes of preterm prelabor rupture of membranes at Aswan University Hospital.

Patients and methods: This observational descriptive study included 100 women with preterm prelabor rupture of the membranes, attending at Department of Obstetrics and Gynecology, Aswan University

Hospital. This study was conducted between October 2017 to October 2018.

Results: Fetal outcomes observed as : The mean of NICU stay was $5.67 \pm 8.3$ SD while prematurity was the most common neonatal complication by $16 \%$ then RDS by $52 \%$ while the overall neonatal mortality was $8 \%$; $45 \%$ of neonates did not need NICU while the maximum NICU stay was 40 days by $2 \%$. Correlations between the latency period and fetal outcomes showed that: shorter latency period $<2$ weeks increase prevalence of preterm delivery and increase prevalence of RDS while longer latency period $>2$ weeks increase prevalence of neonatal sepsis and NEC, while perinatal mortality are nearly equal in both group.

Conclusion: Perinatal morbidities and mortality also affected by the preference of conservation as this study found high incidence of perinatal morbidities like: prematurity by $53 \%$ then RDS by $52 \%$ then Neonatal sepsis by $16 \%$.
\end{abstract}

Keywords: Maternal, Fetal outcomes, Preterm Prelabor Rupture of Membranes, Aswan University Hospital.

\section{INTRODUCTION}

Preterm premature rupture of membranes (PPROM) is the spontaneous rupture of the fetal membranes during pregnancy before 37 weeks gestation in the absence of regular painful uterine contractions. Preterm premature rupture of membranes (PPROM) complicates 3-8\% of pregnancies and leads to one third of preterm deliveries. It can lead to significant fetal perinatal morbidity such as respiratory distress syndrome, neonatal sepsis, umbilical cord prolapse, placental abruption and fetal death ${ }^{(\mathbf{1})}$.

It can also lead to maternal morbidity such as postpartum endometritis, disseminated intravascular coagulopathy, maternal sepsis, delayed menses and Asherman syndrome. PPROM is an important cause of perinatal morbidity and mortality because it is associated with brief latency from membrane rupture to delivery, perinatal infection and umbilical cord compression due to Oligohydramnios ${ }^{(\mathbf{1}, \mathbf{2})}$.

The etiology is multifactorial, numerous risk factors are associated with PPROM such as black race, lower socioeconomic status, smokers, past history of sexually transmitted infections, previous preterm delivery, polyhydraminos, multiple pregnancy and procedures such as cerclage and amniocentesis ${ }^{(\mathbf{1}, \mathbf{2})}$.

Clinical diagnosis may be easy when patients are presenting with heavy watery vaginal discharge or when clear fluid can be seen leaking from the cervical os. However, recent data suggest that in $47 \%$ of the cases, clinicians are uncertain regarding the diagnosis of PPROM based on clinical examination by sterile speculum examination and patient history alone ${ }^{(3)}$.

Diagnosis is indeed difficult when leakage of fluid is tiny and/or intermittent and/or ultrasound examination shows a normal to low index of amniotic fluid. In these cases, noninvasive biochemical tests can help in diagnosing PPROM (4).

'Classic' tests are represented by an alkaline $\mathrm{pH}$ of the cervicovaginal discharge, which is typically demonstrated by seeing whether discharge turns yellow nitrazine paper to blue (nitrazine test); and/or microscopic ferning of the cervicovaginal discharge on drying. Evidence of diminished amniotic fluid volume alone cannot confirm the diagnosis but may help to suggest it in the appropriate clinical setting ${ }^{(5)}$.

The effects of cervicitis, vaginitis (bacterial vaginosis), and contamination with 
blood, urine, semen, or antiseptic agents on traditional nitrazine or $\mathrm{pH}$-based technologies has been widely documented and shown to lead to high false-positive rates ${ }^{(6)}$.

Because of the limitations with the current standard for the diagnosis of PPROM (History, clinical assessment of pooling, nitrazine, and/or ferning), investigators have long been searching for an alternative and more objective test. Such tests are based primarily on the identification in the cervicovaginal discharge of one or more biochemical markers that are present in the setting of ROM, but absent in women with intact membranes. Several such markers have been studied, including $\alpha$-fetoprotein (AFP), fetal fibronectin (fFN), Insulin-like growth factorbinding protein-1 (IGFBP-1), prolactin, diamine oxidase activity, $\beta$-subunit of human chorionic gonadotropin $(\beta-\mathrm{hCG})$ and placental $\alpha$ microglobulin-1 in order to identify PPROM ${ }^{(7)}$.

\section{Objectives:}

Studying the outcomes (Maternal and Neonatal outcomes) of pregnancies complicated with PPROM between $28 \mathrm{~W}+0 \mathrm{D}$ to $36 \mathrm{~W}+6 \mathrm{D}$ Gestation at Aswan University Hospital can help identifying the benefits of which protocol of management upon fetuses minimizing morbidities like neonatal sepsis and upon maternal morbidities like chorioamnionitis.

The aim of the current work was to determine the maternal and fetal outcomes of preterm prelabor rupture of membranes at Aswan University Hospital.

\section{PATIENTS AND METHODS}

This observational descriptive study included 100 women with preterm prelabor rupture of the membranes, attending at Department of Obstetrics and Gynecology, Aswan University Hospital. Written informed consent of all the subjects for acceptance of the operation was obtained. This study was conducted between October 2017 to

October 2018.

Ethical approval and written informed consent: An approval of the study was obtained from Aswan University Academic and Ethical Committee.

Detailed History was taken from every patient:

- Personal History: Name, age, residence; occupation, duration of marriage and any special habits of medical importance especially smoking.

- History of Present Illness: Gush of clear odorless vaginal fluid, abdominal pain, offensive discharge and fever.
- Menstrual History: Calculating the gestational age from the first day of last menstrual period if the patient is sure for her date.

- Medical History: Identifying risk factors of PPROM: urinary tract infection, present and or recurrent vaginal infection

- Surgical History: Presence of cerclage or previous trail of amniocentesis during this pregnancy

- Past History: previous pregnancies complicated by PPROM or preterm labour.

Clinical Examination of each patient: General examination:

1. Vital signs: Pulse, blood pressure measurement and temperature chart.

2. Height, weight and calculation of body mass index.

Abdominal examination:

1- Inspection for shape, contour, pigmentation and scars.

2- Fundal level, fundal grip, umbilical grip, first pelvic grip and second pelvic grip.

3- Auscultation of fetal heart sounds by pinard's stethoscope or by sonicaid.

Ultrasonography:

1. For fetal biometry confirming the gestational age.

2. Amniotic fluid index measurement.

3. Assessment of fetal well-being by biophysical profile.

4. Placental grade and excluding placental separation.

5. Detection of any fetal gross anomalies

Per vaginal Examination: Sterile speculum confirming pooling of amniotic fluid from the cervical os.

Laboratory Investigations: Complete blood count, urine analysis, C-reactive protein, Kidney and liver function tests and viral markers.

\section{Regarding Treatment:}

All patients then admitted to antenatal care unite waiting 24 hours for spontaneous onset of labor and completing their investigations excluding chorioamnionitis, placental separation, and fetal compromise .

1. Bed rest is generally recommended (in an attempt to enhance re-accumulation of amniotic fluid and to improve uteroplacental perfusion and thereby fetal growth).

2. Steroid therapy: all women with PPROM received single course $8 \mathrm{mg}$ dexamethasone 4 doses every 12 hour at up to $36 \mathrm{w}+6 \mathrm{D}$ of gestation. 
3. Antibiotics: all women received Sulbactamampicillin ( $2 \mathrm{~g} /$ day, intravenously for 2-5 days) was initiated then erythromycin / azithromycin $500 \mathrm{mg}$ oral as a prophylaxis against GBS colonization.

4. Oral or IV tocolysis: for up to 48 hours .by $\mathrm{Mg}$ Sulphate, $10 \mathrm{mg}$ ritodrine, isoxsuprine for cases who developed preterm labour pain in the absence of chorioamnionitis, placental separation or fetal compromise.

5. Treatment of underlying risk factor: urinary tract infection and vaginal infection.

\section{Follow up:}

We followed up the cases to detect any maternal and fetal complications (preclinical chorioamnionitis or fetal compromise) till the onset of spontaneous labor or reaching maturity .

1- Maternal pulse and temperature charts were followed to detect early signs of chorioamnionitis.

2- Serial CRP to detect rising titer twice weekly

3- CBC twice weekly to detect new onset leukocytosis.

4- Assessment of fetal well-being by daily FHR count and biophysical profile every other day. To detect early fetal compromise.

5- Detection of development of labour pains.

6- Detection of development of vaginal bleeding suggesting placental separation that could be managed conservatively in cases of mild vaginal bleeding.

7- Clinical chorioamnionitis was diagnosed when the temperature was elevated to $38^{\circ} \mathrm{C}$.

8- In the presence of established labor, moderate to severe bleeding due to placental abruption, fetal distress or intrauterine infection termination of pregnancy was considered.

9- Outpatient monitoring of PPROM after selection was done by a consultant obstetrician after a period of 48-72 hours of inpatient observation and were advised about the manifestations of chorioamnionitis and under what circumstances they should seek medical advice.

\section{Types of outcome measures:}

Indices of perinatal morbidity, maternal morbidity and obstetric interventions.

A) Neonatal outcomes: neonatal outcome were taken into consideration in regard to statistical variables were categorized into :

- RDS.

- Narcotizing Enterocolitis (NEC).

- Early neonatal sepsis, pneumonia.

- Mortality (Neonatal death, IUFD or Stillbirth)
- Duration of stay at neonatal intensive care unit (NICU)

B) Maternal outcomes:

- Complications of PPROM (chorioamnionitis, placental separation, cord prolapse )

- Latency period (period from onset PPROM to Delivery)

- Mode of delivery (vaginal delivery or cesarean section).

- Occurrence of Postpartum Hemorrhage.

- Presence of tocolysis, corticosteroids or antibiotics use.

- Postpartum fever / puerperal sepsis.

- Surgical site infection.

\section{Statistical Analysis}

Variables like age, parity, duration of pregnancy, and mode of delivery, maternal and fetal condition were recorded. the results were illustrated in the form of tables and graphs. All relevant data were compiled and entered into computer using computer based software SPSS (v23) for appropriate analysis. Quantitative variable like maternal age and gestational age were presented by mean \pm standard deviation. Frequency and percentage were computed for presentation of parity, mode of delivery, induction to delivery interval and maternal complications. Quantitative data were analyzed by independent t-test and ANOVA test where: $\mathrm{P}$ value $<0.05$ was the level of significance.

\section{RESULTS}

Table (1): Maternal Demographic Data:

\begin{tabular}{|l|l|l|}
\hline \multicolumn{1}{|c|}{ Item } & Number & Percent \\
\hline $\begin{array}{l}\text { Maternal age (years) } \\
\text { (Mean + SD) (Range) }\end{array}$ & $\begin{array}{l}\mathbf{2 8} \pm \mathbf{6} \\
\mathbf{1 9}-\mathbf{4 2}\end{array}$ & \\
\hline Parity & & \\
\hline Primigravida & $\mathbf{3 0}$ & $\mathbf{3 0 \%}$ \\
\hline Multigravida & $\mathbf{6 2}$ & $\mathbf{6 2 \%}$ \\
\hline Grand Multipara & $\mathbf{8}$ & $\mathbf{8 \%}$ \\
\hline Residency & & \\
\hline Rural & $\mathbf{4 0}$ & $\mathbf{4 0 \%}$ \\
\hline Urban & $\mathbf{6 0}$ & $\mathbf{6 0 \%}$ \\
\hline Occupation & & \\
\hline Housewife & $\mathbf{8 0}$ & $\mathbf{8 0 \%}$ \\
\hline Working & $\mathbf{2 0}$ & $\mathbf{2 0 \%}$ \\
\hline Educational Level & & \\
\hline Illiterate and 1ry school & $\mathbf{5 5}$ & $\mathbf{5 5 \%}$ \\
\hline 2ry and high school & $\mathbf{4 5}$ & $\mathbf{4 5 \%}$ \\
\hline
\end{tabular}

Maternal demographic data whereas the mean maternal age was $28 \pm 6$ SD years old, mostly affecting multigravida by $62 \%$ and the 
majority of cases were at low educational level by $55 \%$.

Table (2): Risk Factors of PPROM:

\begin{tabular}{|c|c|c|}
\hline Item & Number & Percent \\
\hline $\begin{array}{l}\text { Past history of } \\
\text { PPROM }\end{array}$ & 19 & $19 \%$ \\
\hline $\begin{aligned} & \text { Vaginal Infection } \\
& \text { - } \text { Candidiasis } \\
& \text { - } \text { Mixed } \\
& \text { infection } \\
&\end{aligned}$ & $\begin{array}{l}62 \\
28 \\
33\end{array}$ & $\begin{array}{l}62 \% \\
28 \% \\
33 \%\end{array}$ \\
\hline $\begin{array}{l}\text { Urinary tract } \\
\text { infection }\end{array}$ & 28 & $28 \%$ \\
\hline
\end{tabular}

Risk factors of PPROM Demonstrates that: vaginal infection during pregnancy presented by $62 \%$ while UTI during pregnancy presented by $28 \%$ of cases.

\section{Table (3): Post-natal maternal outcomes} (Complications):

\begin{tabular}{|l|l|l|}
\hline Item & Number & Percent \\
\hline Puerperal sepsis & $\mathbf{1 9}$ & $\mathbf{1 9 \%}$ \\
\hline Wound infection & $\mathbf{1 2}$ & $\mathbf{1 2 \%}$ \\
\hline
\end{tabular}

Post natal outcomes. The puerperal sepsis and wound infection were represented by $12 \%$ and $19 \%$ respectively

Table (4): Indications of cesarean delivery:

\begin{tabular}{|l|l|l|l|}
\hline Indication & Number & Percent & $\begin{array}{l}\text { Cumulative } \\
\text { Percent }\end{array}$ \\
\hline Previous scar & 37 & $53 \%$ & 53 \\
\hline $\begin{array}{l}\text { Maturity } \\
\text { Reached }\end{array}$ & 13 & $18 \%$ & 72 \\
\hline Fetal distress & 11 & $16 \%$ & 88 \\
\hline chorioamnionitis & 7 & $10 \%$ & 98 \\
\hline $\begin{array}{l}\text { Ante partum } \\
\text { Hge }\end{array}$ & 1 & $1 \%$ & 100 \\
\hline Total & 69 & $100 \%$ & $100 \%$ \\
\hline
\end{tabular}

$53 \%$ of total cesarean delivery in this study are due to previous cesarean delivery then $18 \%$ due to reaching Maturity( in the presence of previous scar or failed induction of labor). While out of 20 cases complicated by placental separation, 19 cases managed conservatively while only 1 case terminated by CS.

Table (5): Treatment options:

\begin{tabular}{|c|c|c|}
\hline Item & Number & Percent \\
\hline Antibiotics & 100 & $100 \%$ \\
\hline Steroids & 98 & $98 \%$ \\
\hline MgSo4 & 16 & $16 \%$ \\
\hline $\begin{array}{l}\text { Tocolysis (B } \\
\text { Agonist) }\end{array}$ & 55 & $55 \%$ \\
\hline $\begin{array}{l}\text { Mode of } \\
\text { management } \\
\text { Conservative } \\
\text { management } \\
\text { Active } \\
\text { management }\end{array}$ & $\begin{array}{l}73 \\
27\end{array}$ & $\begin{array}{l}73 \% \\
27 \%\end{array}$ \\
\hline
\end{tabular}

Showed that almost all cases received antibiotics and corticosteroids by $100 \%$ and $98 \%$ respectively. While $71 \%$ of cases suffering from labour pains received tocolysis in the form of B agonist by $55 \%$ then by $\mathrm{MgSo} 4$ by $16 \%$. Conservative management of PPROM cases predominated by $73 \%$.

Table (6): Neonatal outcomes (complications)

\begin{tabular}{|l|l|l|}
\hline Item & Number & Percent \\
\hline Prematurity & $\mathbf{5 3}$ & $\mathbf{5 3 \%}$ \\
\hline RDS & $\mathbf{5 2}$ & $\mathbf{5 2 \%}$ \\
\hline $\begin{array}{l}\text { NICU admission } \\
\text { NICU stay } \\
\text { (Mean } \pm \text { SD) } \\
\text { Peak }\end{array}$ & $\mathbf{5 5}$ & $\mathbf{5 5 \%}$ \\
\hline Neonatal sepsis & $\mathbf{7}(\mathbf{7}$ days $)$ & $\mathbf{7 \%}$ \\
\hline NEC & $\mathbf{1 6}$ & $\mathbf{1 6 \%}$ \\
\hline $\begin{array}{l}\text { perinatal } \\
\text { mortality }\end{array}$ & $\mathbf{3}$ & $\mathbf{3 \%}$ \\
$\begin{array}{l}\text { IUFD } \\
\text { - Neonatal } \\
\text { death. }\end{array}$ & $\mathbf{2}$ & $\mathbf{8 \%}$ \\
- Stillbirth. & $\mathbf{5}$ & $\mathbf{2 \%}$ \\
\hline \multicolumn{2}{|l|}{ Show Th m } & $\mathbf{1 \%}$ \\
\hline
\end{tabular}

Shows The mean of NICU stay was

$5.67 \pm 8.3$ while Prematurity was the most common neonatal complication by $53 \%$ then RDS by $52 \%$ while the overall neonatal mortality was $8 \%$ 


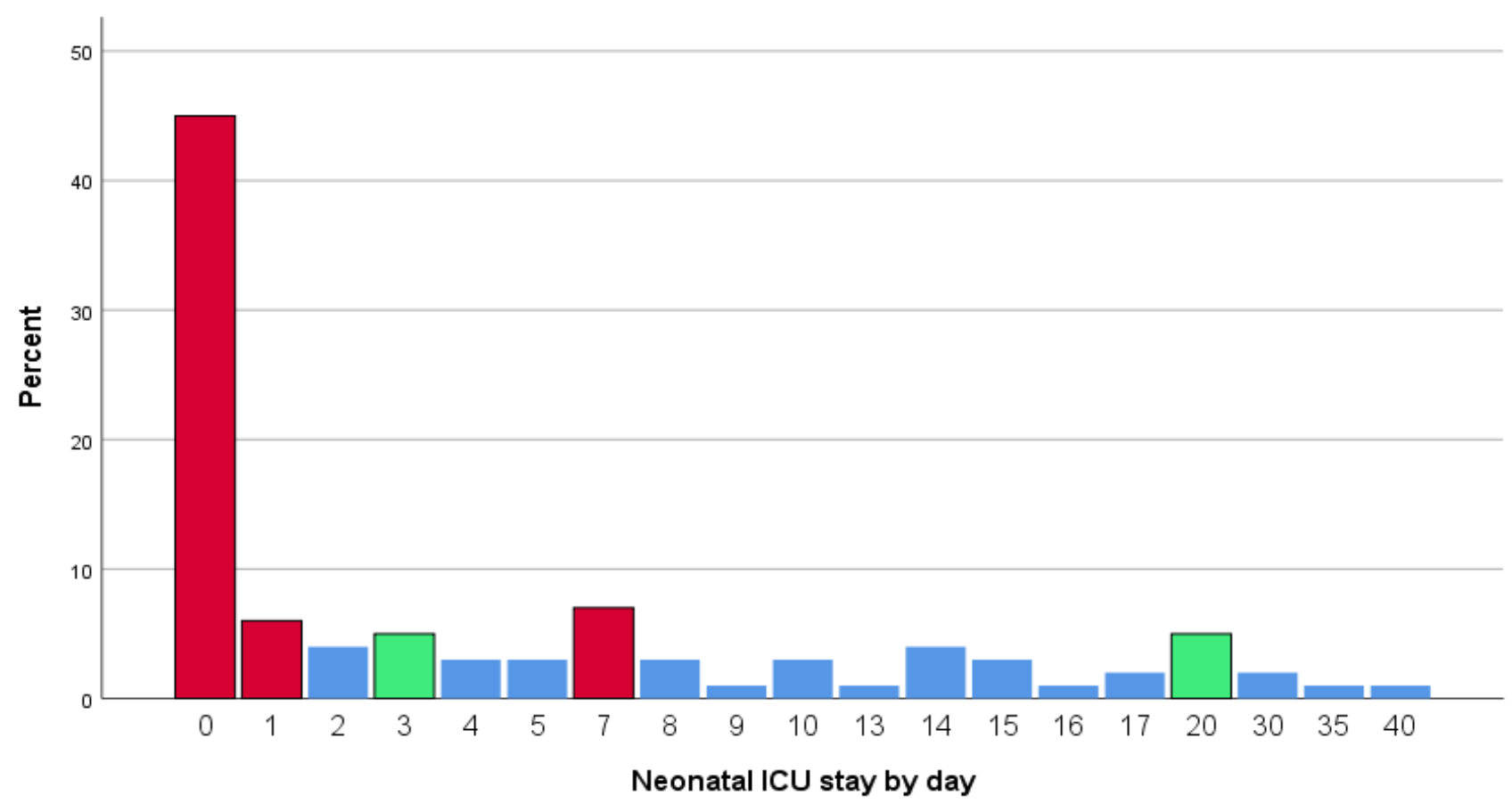

Figure (1): NICU stay by Days.

Shows NICU stay of cases PPROM cases in Aswan University Hospital during 2018/2019 shows that 45\% of neonates did not need NICU while the maximum NICU stay was 40 days by $2 \%$.

Table (7): Perinatal morbidity and mortality in relation to Duration of PPROM (Latency Period):

\begin{tabular}{|l|l|l|l|l|}
\hline $\begin{array}{l}\text { Perinatal morbidity } \\
\text { And mortality }\end{array}$ & $\begin{array}{l}<\mathbf{7 2 h o u r} \\
\text { Number (percentage ) }\end{array}$ & $\begin{array}{l}\text { 72hr-2weeks } \\
\text { Number (Percentage) }\end{array}$ & $\begin{array}{l}\text { >2 weeks } \\
\text { Number } \\
\text { (percentage) }\end{array}$ & $\begin{array}{l}\text { Total } \\
\text { number }\end{array}$ \\
\hline Preterm & $7(13 \%)$ & $27(51 \%)$ & $19(36 \%)$ & 53 \\
\hline RDS & $7(14 \%)$ & $23(44 \%)$ & $22(42 \%)$ & 52 \\
\hline Neonatal sepsis & zero & $3(20 \%)$ & $13(80 \%)$ & 16 \\
\hline NEC & zero & $1(33 \%)$ & $2(67 \%)$ & 3 \\
\hline Perinatal mortality & $1(12 \%)$ & $3(38 \%)$ & $4(50 \%)$ & 8 \\
\hline
\end{tabular}

Shorter latency period $<2$ weeks increases incidence of preterm delivery and increase incidence of RDS

(statistically significant negative correlation with $P$ value $<0.05$ ). While longer latency period $>2$ weeks increases incidence of neonatal sepsis and NEC. (Statistically significant positive correlation with $P$ value $<0.05$ ). While perinatal mortality was nearly equal in both group but significantly decreased when the latency $<72$ hours.

\section{DISCUSSION}

This study obtained the maternal characteristics from all cases suffering from PPROM and they were found to be as follow: The cases were selected from all age groups; maternal age ranged between 19- 42 years and (Mean \pm SD) age was $28 \pm \mathbf{6}$ years.

Agreeing with Mohan et al. (8), Mercy and Abiramavalli ${ }^{(9)}$, Mohokar et al. ${ }^{\left({ }^{(1)}\right)}$ and Shweta and Patil (11) obtained the same sample as they analyzed patients $<20$ years and $>30$ years age and found that the most affected age group was between 20-30 years age.

This study found PPROM was common in multigravidas $70 \%$ due to possible long-standing infection, previous trauma to the cervix and patulous os; and 30\% among Primigravida.

Agreeing with Mohan et al. ${ }^{(8)}$, Mercy and Abiramavalli ${ }^{(9)}$, Mohokar et al. (10) “ and Shweta and Patil (11) as they found 39\%, $48 \%$ and $53 \%$ of their total number among primigravida respectively and $61 \%, 52 \%$ and $47 \%$ were multigravida respectively .

Disagreeing with Mercy and Abiramavalli (9) as they found that Primigravida are at higher risk to develop PPROM by $67 \%$ comparable to other mentioned studies.

This study also found the prominent risk factors to develop PPROM were: genital tract infection during current pregnancy accompanied $62 \%$ of cases with PPROM then urinary tract infection by $28 \%$ then urinary tract infection by $19 \%$.

Disagreeing with Mohan et al. ${ }^{(8)}$ that found $29 \%$ of cases had genital tract infection during current pregnancy then $28 \%$ of cases had past history of PPROM then $16 \%$ had urinary tract infection and 
Shweta and Patil ${ }^{(11)}$ that found $6 \%$ of total analyzed patients had previous history of PPROM during previous pregnancies and $6 \%$ of them had urinary tract infection during current pregnancy.

This study also found the most common gestational age group was between 32-36 weeks by $60 \%$ peaked at 34 weeks by $20 \%$.

Agreeing with Mercy and Abiramavalli (9) that found the peak gestational age group complicated by PPROM was between $34-36$ weeks gestation by $20 \%$.

Disagreeing with Mohan et al. ${ }^{(8)}$ that found the most affected Gestational age group was between 35 week to 36 weeks+ 6days by $60 \%$ and Shweta and Patil ${ }^{(11)}$ that found the most affected gestational age group was between 35 weeks and 36 week+6days gestation by $75 \%$ among total analyzed patients.

This study observed the preference of conservation during management of PPROM and that appeared in the latency period that ranged between 156 and peaked at 7 days by $15 \%$ in attempt to prolong the pregnancy to avoid iatrogenic prematurity so the gestational age at delivery was by mean 34.6 weeks \pm 1.89 SD.

Disagreeing with other studies as they conserved PPROM cases not more than 72 hours; Mohan et al. ${ }^{(8)}$ and Shweta and Patil ${ }^{(11)}$ found the latency period ranged between $24-72$ hours with Peak group < 24 hours by $35 \%$ and $24-48$ hours with peak < 24 hours by $53 \%$ respectively while Mercy and Abiramavalli (9) found The latency period divided between $<24$ hours presented by $10 \%$ and $>24$ hours presented by $90 \%$ while Mohokar et al. ${ }^{(10)}$ found the latency period range between $12-36$ hours and peaked at $<12$ hours by $29 \%$.

This study found that PPROM increased prevalence of LSCS by $69 \%$ while vaginal delivery was $31 \%$.

Disagreeing with the other studies Mohan $\boldsymbol{e t}$ al. ${ }^{(8)}$, Mercy and Abiramavalli ${ }^{(9)}$, Mohokar et al. ${ }^{(10)}$ and Shweta and Patil ${ }^{(11)}$ as they found vaginal deliveries predominated by $75 \%, 77 \%, 78 \%$ and $88 \%$ respectively as termination of pregnancy was done by induction of labour when there is no contraindication to vaginal delivery.

This study found that the most common indication of LSCS was previous LSCS presented by $53 \%$ while development of fetal distress by $16 \%$, reaching maturity by $18 \%$ (in the presence of previous scar or when induction of labour was failed or contraindicated ), suspected chorioamnionitis by $10 \%$ and moderate to severe ante partum hemorrhage (due to placental separation ) by $1 \%$.

Disagreeing with the other mentioned studies: Shweta and Patil (11) "found non cephalic presentation, fetal distress and presence of previous scar were $22.5 \%, 51 \%, 11 \%$ respectively. While Mohan et al. ${ }^{(8)}$ found non cephalic presentation, failed induction of labour, fetal distress and presence of previous scar were the causes of cesarean delivery by $46.8 \%, 12 \%, 16,6 \%$ and $10.5 \%$ respectively . While, Mohokar et al. (10) found that non cephalic presentation, failed induction of labor fetal distress and presence of previous scar were the causes of cesarean delivery by $40 \%, 12 \%, 24 \%$ and $12 \%$ respectively.

Discussing maternal morbidities observed that This study found a significantly increased rate of antepartum hemorrhage due to placental separation by $20 \%$, while wound infection following PPROM presented by $19 \%$ and puerperal sepsis by $12 \%$ while in $7 \%$ of cases chorioamnionitis was diagnosed .

Disagreeing with this study: Mohokar et al. (10) found chorioamnionitis was the leading maternal morbidity by $12 \%$ then wound infection by $1 \%$ then postpartum hemorrhage by $1 \%$. while Shweta and Patil (11) also found puerperal sepsis predominated by $11 \%$ then chorioamnionitis by $3 \%$ then wound infection by 3\% while Mercy and Abiramavalli (9) found wound infection following PPROM by $7 \%$, puerperal sepsis by $1 \%$ while zero $\%$ of cases complicated by chorioamnionitis and postpartum hemorrhage by $3 \%$.

This study found that the most common perinatal morbidity is prematurity by $53 \%$ then RDS by $52 \%$ then Neonatal sepsis by $16 \%$ then necrotizing enterocolitis by $3 \%$ while the perinatal mortality reached $8 \%$ among total cases.

Agreeing with Mercy and Abiramavalli (9), Mohokar et al. ${ }^{(10)}$ and Shweta and Patil ${ }^{(11)}$ as they found prematurity is the leading perinatal morbidity by $63 \%, 26 \%$ and $27 \%$ respectively then neonatal sepsis by $30 \%, 14 \%$ and $14 \%$ respectively.

Disagreeing with Mohan et al. 2017 that found the leading perinatal morbidity was neonatal sepsis $6.5 \%$ then RDS by $4.4 \%$ then NEC by $2 \%$.

This study found high prevalence of perinatal mortality was represented by $8 \%$ of PPROM cases.

Agreeing with Mohan et al. ${ }^{(8)}$, Mercy and Abiramavalli ${ }^{(9)}$, Mohokar et al. ${ }^{(10)}$ and Shweta and Patil ${ }^{(11)}$ as they found high prevalence of perinatal mortality presented by $15 \%, 7 \%, 11 \%$ and $5 \%$ respectively .

This study found an increase in preterm labor and in RDS ( $51 \%$ and $44 \%$ respectively ) when the latency period decrease $<2$ weeks compared to a decrease in preterm labor and RDS (36\% and $42 \%$ respectively) when latency period increase $>2$ weeks. While neonatal sepsis and NEC decrease (20\% and $33 \%$ respectively) when latency period decrease compared to increase in neonatal sepsis and NEC $(80 \%$ and $67 \%$ respectively) when latency period increase while perinatal mortality was not affected by latency period. 
Agreeing with Shweta and Patil ${ }^{(11)}$ that found that an increase in neonatal sepsis and decreased RDS (presented by $33 \%$ and $16 \%$ respectively ) in relation to increased latency period $>72$ hours while neonatal sepsis decreased and RDS increased ( $20 \%$ and $28 \%$ respectively ) when latency period decreased <24 hours . But this study had not discussed the effect of latency period on 7 perinatal mortality cases.

Disagreeing with Mohan et al. (8) and Mohokar et al. (10) as they found increased total perinatal morbidities (by 60\% and 32\% respectively) with prolonged latency compared to decreased total perinatal morbidities ( by $10 \%$ and $16 \%$ respectively ) with short latency period .

Also disagreeing with Mohan et al. ${ }^{(8)}$ and Mohokar et al. ${ }^{(10)}$ as they found increased perinatal mortality ( by $28 \%$ and $2.3 \%$ respectively ) when latency period was prolonged while the perinatal mortality decreased (by 3 and 1.6 respectively) with short latency period.

\section{CONCLUSION}

As demonstrated by the results, it could be concluded that:

1. PPROM was common among multigravidas by $70 \%$. and the major risk factor of PPROM identified by this study was vaginal infection that accompanied $62 \%$ of cases

2. This tertiary unite gave preference to conservation of pregnancy in attempt to prolong the pregnancy to avoid iatrogenic prematurity due to the continuous shortage of NICU places and unavailability of therapeutic options like surfactant and total parenteral nutrition in the NICU at Aswan University Hospital .

3. The preference to conserve PPROM cases was reflected on significantly increased rate of maternal morbidities like: wound infection following PPROM by $19 \%$ and puerperal sepsis by $12 \%$ while clinical chorioamnionitis was diagnosed by $7 \%$.

4. On the other hand perinatal morbidities and mortality also affected by the preference of conservation as this study found high incidence of perinatal morbidities like: prematurity by $53 \%$ then RDS by $52 \%$ then Neonatal sepsis by $16 \%$ then necrotizing enterocolitis by $3 \%$ while the perinatal mortality reached $8 \%$.

5. The latency period affected the perinatal morbidity, as this study found an increase in preterm delivery and RDS by $51 \%$ respectively $44 \%$ when the latency period decrease while neonatal sepsis and NEC decreased by $20 \%$ and $33 \%$ respectively when latency period decreased .

6. This study found that Aswan University Hospital preferred termination of pregnancy by cesarean delivery with Incidence of $69 \%$ while vaginal delivery was $31 \%$.

\section{RECOMMENDATIONS}

1. Further Randomized Controlled Trials and further descriptive studies studying wide range of population should be done to assess the applicability of diagnostic tools and to identify which best management strategy that should be applied to our practice.

2. More available NICU places should be available to the obstetric department to give no chance to delay termination of pregnancy once the decision had taken.

\section{REFERENCES}

1. Medina TM, Hill DA (2006): Preterm Premature Rupture of Membranes: Diagnosis and management. Am Fam Physician, 73: 659-664.

2. Sedigheh B, Borna H, Hantoushzadeh S (2004): 'Perinatal outcome in preterm premature rupture of membranes with Amniotic fluid index $<5$ (AFI $<5)$. BMC Pregnancy and Childbirth, 4 (1): 15-17.

3. Neil PR, Wallace EM (2010): Is Amnisure ${ }^{\circ}$ useful in the management of women with prelabour rupture of the membranes?. Australian and New Zealand Journal of Obstetrics and Gynaecology, 50 (6): 534-538.

4. DiRenzo GC, Roura LC, Facchinetti F et al. (2011): Guidelines for the management of spontaneous preterm labor: identification of spontaneous preterm labor, diagnosis of preterm premature rupture of membranes, and preventive tools for preterm birth. The Journal of MaternalFetal and Neonatal Medicine, 24: 659-667.

5. Mercer BM (2005): Preterm premature rupture of the membranes: current approaches to evaluation and management. Obstet Gynecol Clin North Am., 32: 411428.

6. ACOG Committee on Practice Bulletins-Obstetrics (2007): ACOG Practice Bulletin No. 80: premature rupture of membranes. Clinical management guidelines for obstetrician gynecologists. Obstet Gynecol., 109: 10071019.

7. Chen FCK, Dudenhausen JW (2008):Comparison of two rapid strip tests based on IGFBP-1 and PAMG-1 for the detection of amniotic fluid. American Journal of Perinatology, 25 (04): 243-246.

8. Mohan SS, Thippeveeranna C, Singh NN et al. (2017): Analysis of risk factors, maternal and fetal outcome of spontaneous preterm premature rupture of membranes: a cross sectional study. International Journal of Reproduction, Contraception, Obstetrics and Gynecology, 6 (9): 3781-3787.

9. Mercy RR, Abiramavalli K (2016): Perinatal and maternal outcome in premature rupture of membranes. Proteus, 2: 13-33.

10. Mohokar A, Bava AK, Nandanwar YS (2015): Analysis of maternal and perinatal outcome in cases of preterm premature rupture of membranes. Bombay Hospital J., 57 (3): 285-290.

11. Shweta P, Patil V (2014): Maternal and foetal outcome in premature rupture of membranes. IOSR-JDMS., 13 (12): 56-83. 